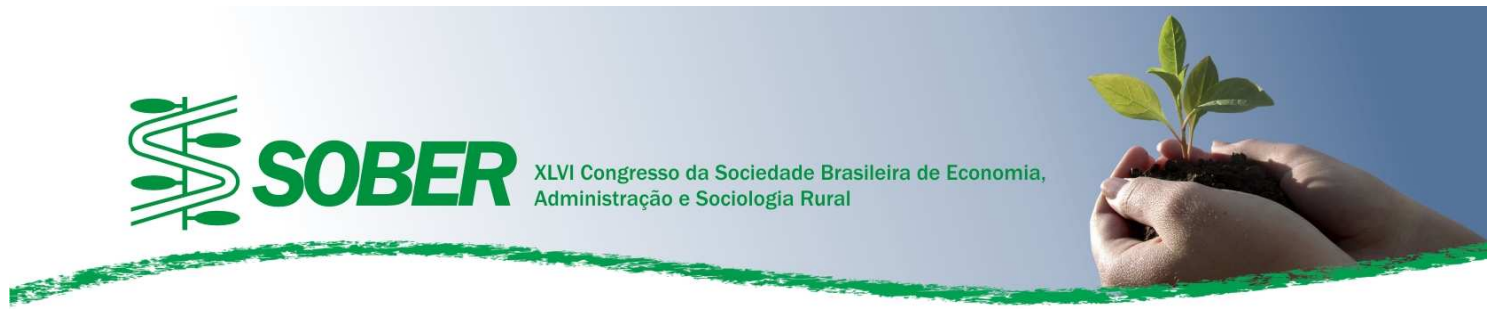

ANÁLISE DA VIABILIDADE SÓCIO-AMBIENTAL DA FRUTICULTURA IRRIGADA NO BAIXO
JAGUARIBE, CEARÁ

JOSE CESAR PINHEIRO; CECÍLIA REIS AMARAL;

PRODEMA-CE - MESTRE

FORTALEZA - CE - BRASIL

jcvpinhe@ufc.br

APRESENTAÇÃO ORAL

Instituições e Desenvolvimento Social no Agronegócio

\title{
Título ANÁLISE DA VIABILIDADE SÓCIO-AMBIENTAL DA FRUTICULTURA IRRIGADA NO BAIXO JAGUARIBE, CEARÁ
}

RESUMO: A fruticultura irrigada é uma atividade que vem crescendo no Estado do Ceará, sobretudo em certas regiões favoráveis do Estado. Entre estas regiões encontrase o Baixo Jaguaribe, onde diversas empresas exploram a fruticultura irrigada e procurou-se, nesta pesquisa, avaliar os aspectos sociais e ambientais da atividade. Os aspectos sociais foram avaliados através de entrevistas com funcionários das empresas produtoras de frutas na região e estas abrangeram aspectos como: serviços de educação e saúde nos municípios de residência, habitação, aspectos sanitários, posse de bens duráveis e emprego. Os aspectos e cuidados ambientais das empresas foram avaliados com base em entrevistas com os técnicos responsáveis das empresas por este setor. Foram abordados nas entrevistas itens como: utilização de práticas de conservação do solo, existência de reserva legal na propriedade, controle de pragas e doenças, uso de fogo em atividade agropecuária, sistema de irrigação utilizado, entre outros. A partir das informações obtidas foram calculados dois sub-índices: um de qualidade de vida dos funcionários e outro de viabilidade ambiental. A partir desses dois sub-índices foi obtido um índice de viabilidade sócio-ambiental da fruticultura irrigada nas empresas, ambos apresentaram bons resultados. Verificou-se que as condições de vida dos funcionários são adequadas e que, em geral, são tomados nas propriedades os principais cuidados ambientais necessários. Assim, a fruticultura irrigada vem sendo desenvolvida por empresas e estas tomam os cuidados ambientais necessários, com responsabilidade social.

Palavras-chave: Agricultura Irrigada, Fruticultura, Desenvolvimento Sustentável. 


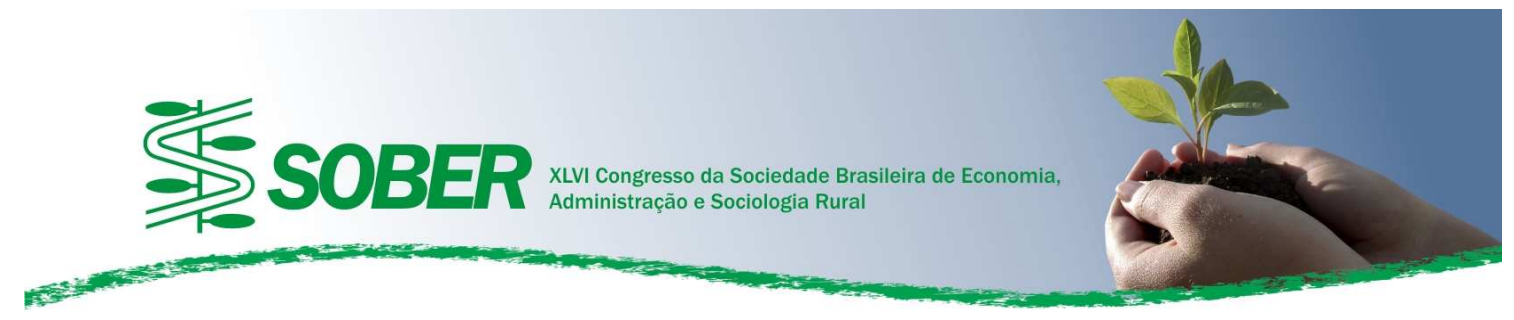

ABSTRACT: The irrigated fruit cultivation is an activity that has been growing in the State of Ceará,especially in certain favourable areas. Among these areas, there is the Low Jaguaribe, where various enterprises explore the activity. To evaluate, therefore, whether the irrigated fruit cultivation developed in the region has been contributing for the sustainable development, this research tried to evaluate the social and environmental aspects of the activity. The social matters were evaluated through interviews with the workers of the enterprises that produce fruits in the region. Were interviewed people who worked directly in the production (cultivation, harvest and after harvest cares) because these are the majority of workers in these enterprises. The interviews included items such as: education and health public services in the municipalities of residence, housing, sanitary aspects, possession of lasting consumer goods and job. The environmental matters of the activity were evaluated through interviews with the responsible technicians in the enterprises visited. Items such as use of soil conservation practices, existence of legal reserve in the property, plagues and illnesses control, fire use in the agricultural activity, kind of irrigation system used, among others, were included in the interviews. Starting from these information, two indexes were calculated: one of workers' quality of life and another of environmental viability. Starting from these two indexes, it was obtained an index of socio-environmental viability of the irrigated fruit cultivation in the region's enterprises visited in the region as environmental and socially viable.

Key-words: irrigated agriculture, irrigated fruit cultivation, sustainable development1.

\section{INTRODUÇÃO}

O Agronegócio foi o setor que nos últimos anos mais contribuiu para o superávit comercial do país. Quando se calcula o produto interno bruto (PIB) agropecuário de forma sistêmica, ou seja, agregando os elos da cadeia produtiva, a sua participação no produto total brasileiro foi de 46\% em 2002 (Gondim, 2004).

Nos dias de hoje, com a consolidação do ideal de Desenvolvimento Sustentável, para que uma atividade, empresa ou país seja considerado bem sucedido, é necessário que ele seja mais do que economicamente viável. É preciso também haver justiça social e respeito aos recursos ambientais. Neste caso é necessário tomar as medidas de manejo cabíveis para preservar a qualidade dos recursos naturais.

No Brasil, o Agronegócio tem gerado impactos ambientais preocupantes em todas as regiões, com maior intensidade nos Cerrados, na Floresta Amazônica e no Nordeste que já inicia um processo de desertificação preocupante. A agricultura foi apontada como a principal forma difusa de poluição pela conferência das Nações Unidas para o Desenvolvimento e o Meio Ambiente (ECO-92), realizada no Rio de Janeiro (KHATOUNIAN, 2001). Alguns dos principais fatores sempre citados como perturbadores do meio ambiente são a ineficiência energética e os impactos decorrentes da erosão e a salinização dos solos, a poluição das águas e dos solos por fertilizantes e agrotóxicos, a contaminação do homem do campo e dos alimentos, o desflorestamento, a diminuição da biodiversidade e o uso predatório dos recursos não renováveis (MAROUELLI, 2003). 
Quanto à questão social, sabe-se da existência no país, até hoje, do trabalho escravo e infantil em algumas localidades, principalmente na região Norte e em lavouras de cana de açúcar no Nordeste. Existe no Brasil uma grande quantidade de trabalhadores agrícolas que não têm como atender às suas necessidades básicas.

O crescimento da fruticultura irrigada no Ceará foi significativo, principalmente nos vales úmidos, onde as condições naturais são mais favoráveis. A Tabela 1, abaixo, mostra esse crescimento, os dados são referentes à fruticultura em geral, já que a Pesquisa Agrícola Municipal do (IBGE) não faz distinção entre fruticultura irrigada ou de sequeiro.

Tabela 1: Evolução da área colhida de algumas frutas do Ceará

\begin{tabular}{c|r|rrr|r}
\hline FRUTAS & \multicolumn{1}{c|}{$\mathbf{1 9 9 8}$} & \multicolumn{1}{c|}{$\mathbf{2 0 0 0}$} & $\mathbf{2 0 0 2}$ & \multicolumn{1}{c}{$\mathbf{2 0 0 4}$} \\
\hline ABACAXI & 9 & 5 & 13 & 293 \\
COCO & 29.725 & 37.316 & 38.799 & 40.063 \\
BANANA & 41.609 & 42.767 & 41.936 & 42.261 \\
MAMÃO & 912 & 1.182 & 1.693 & 1.691 \\
MANGA & 3.738 & 4.270 & 4.515 & 4.795 \\
MELÃO & 1.164 & 2.106 & 3.842 & 4.394 \\
MELANCIA & 291 & 312 & 311 & 463 \\
UVA & 12 & 8 & 59 & 66 \\
TOTAL & 77.460 & 87.966 & 91.168 & 94.026 \\
\hline
\end{tabular}

Fonte: IBGE - Produção Agrícola Municipal

O Governo do Estado do Ceará tem implementado políticas de incentivo a tal atividade aliado ao setor privado. Grandes obras públicas de infra-estrutura foram e vêm sendo construídas no Estado, por exemplo, a CE 377, também chamada de estrada do melão, com 41 quilômetros e inaugurada em 2002; a estrada que corta o município de Quixeré, ligando a área de produção ao município de Bom Sucesso (RN). Outra grande obra construída pelo Governo Federal e participação do Estado, com o objetivo de prover água para irrigação, entre outros fins, foi o Açude Castanhão, que ampliou em $40 \%$ a disponibilidade de água para a agricultura Irrigada (SEAGRI, 2004).

A Tabela 2 mostra o desempenho de alguns produtos da fruticultura do Ceará em 2004, e da mesma forma da tabela anterior, não faz distinção entre fruticultura irrigada ou de sequeiro. Pode-se observar que a banana, o melão e o coco são as frutas com maior valor da produção. $\mathrm{O}$ abacaxi não tinha nenhuma expressão econômica no Ceará, mas vem despontando como o de maior potencial de crescimento na pauta de exportação cearense.

Tabela 2: Desempenho de alguns produtos da fruticultura do Ceará em 2004 


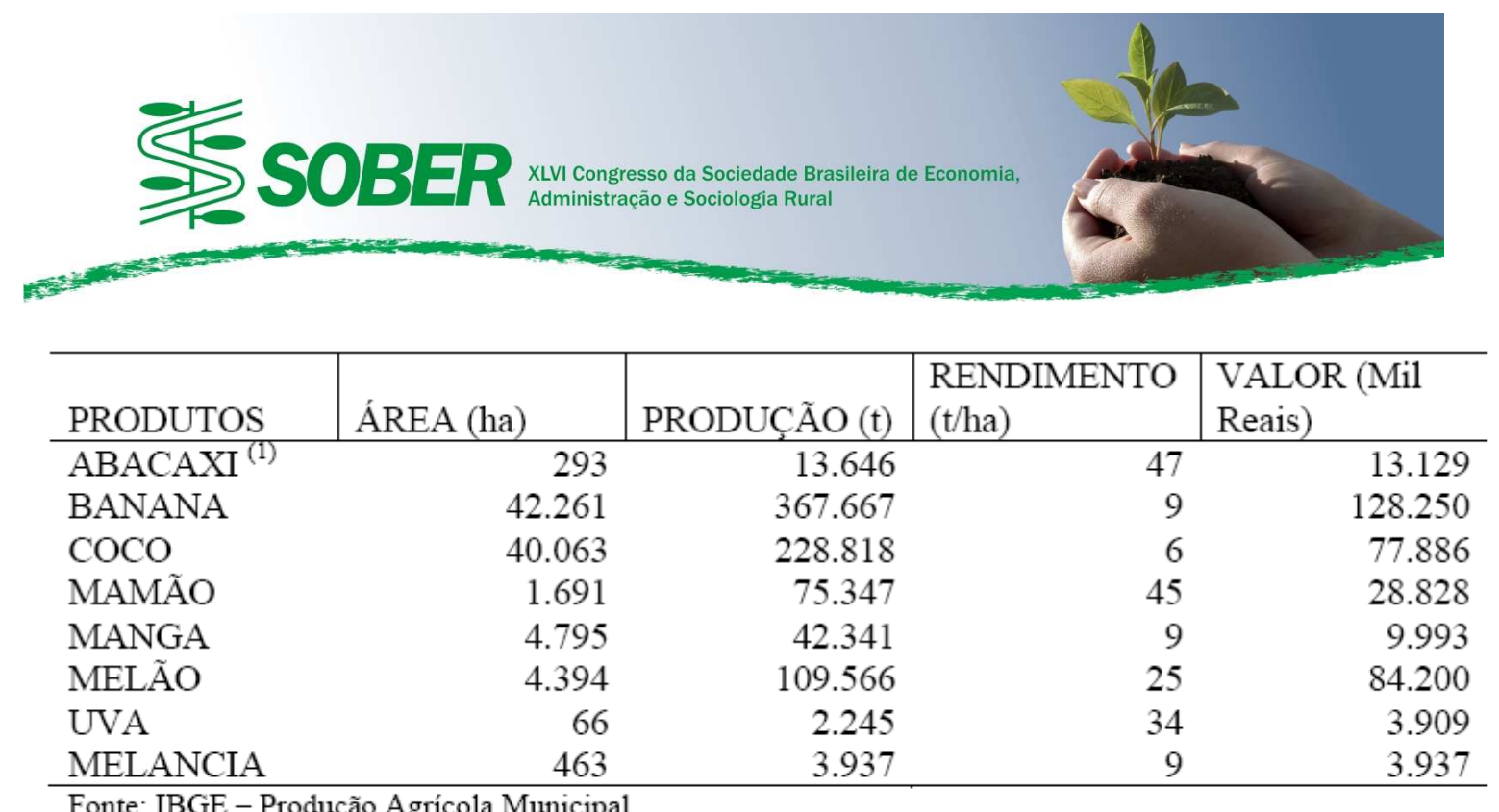

Fonte: IBGE - Produção Agrícola Municipal

(1) A produção de abacaxi é expressa em mil frutos e seu rendimento é expresso em mil frutos por hectare.

Pelo exposto, considera-se importante conhecer melhor os aspectos sociais e ambientais do agronegócio. O presente estudo se deterá na análise da viabilidade sócioambiental do agronegócio da fruticultura irrigada desenvolvido por médias e grandes empresas na região do Baixo Jaguaribe-Ceará.

\section{METODOLOGIA 2.1.Origem dos Dados}

Para a realização desta pesquisa foram utilizados dados primários, obtidos através de entrevistas diretas junto aos funcionários e responsáveis técnicos das empresas produtoras de frutas no Baixo Jaguaribe, no mês de Outubro de 2006. Para analisar as condições de vida dos trabalhadores da atividade, foram entrevistados empregados que trabalhavam diretamente na produção (cultivo, colheita e pós-colheita).

Para focalizar e analisar os cuidados ambientais nas propriedades foram entrevistados os técnicos responsáveis por este setor específico em cada empresa visitada. Foram também utilizados dados secundários de fontes diferentes, principalmente do (IBGE) e da Secretaria da Agricultura do Ceará (SEAGRI).

A definição do número de empresas e funcionários foi baseada no modelo de amostra intencional não probabilística (GIL, 1999). As empresas visitadas faziam parte do rol de produtoras de frutas cadastradas pela SEAGRI no escritório do Agropólo Baixo Jaguaribe, em que constam quinze médias e grandes empresas. Dessa forma, foram visitadas seis empresas distribuídas na região e localizadas nos municípios de Itaiçaba, Icapuí, Limoeiro do Norte e Quixeré. Em cada uma delas foram entrevistados cinco funcionários e o responsável pelo setor ambiental, totalizando trinta funcionários e seis responsáveis técnicos.

A pesquisa não pode ser feita em todas as empresas existentes devido a dificuldades na obtenção de autorização para as entrevistas. O grupo de empresas visitadas abrange um total de 3.190 hectares de área cultivada e possuem um total de 3.029 empregados diretos, entre temporários e permanentes. Quatro dessas empresas atuam no mercado externo.

Para melhor avaliar a viabilidade sócio-ambiental da fruticultura irrigada desenvolvida por empresas no Baixo Jaguaribe foi utilizado e adaptado um índice 
baseado em trabalho de Sousa (2005), composto por dois sub-indices, que abordam as dimensões sociais e ambientais. $\mathrm{O}$ aspecto econômico não foi considerado, até mesmo porque as empresas só desenvolvem a atividade, pelo menos no curto prazo, se forem economicamente viáveis.

Quanto aos aspectos ambientais e sociais, as empresas tendem a utilizar os recursos disponíveis da forma mais intensiva possível, podendo degradar o ambiente e não respeitar os direitos dos trabalhadores. É por isso que esses aspectos geralmente precisam ser fiscalizados pelo governo.

Os indicadores de sustentabilidade são ferramentas que avaliam o progresso em direção a sustentabilidade e sinalizam quanto aos objetivos alcançados e conquistas realizadas. De acordo com Melo (1999), "um indicador é uma medida que sumariza as informações relevantes a respeito de um fenômeno em particular". Em vez de analisar cada aspecto isoladamente, um índice é uma forma de se agregar diversas informações e dar um diagnóstico que abranja diferentes aspectos de uma determinada situação.

\subsection{Dimensão social}

Para avaliar as condições sociais de vida dos trabalhadores da fruticultura irrigada foram utilizados indicadores resultantes da agregação de educação, saúde, habitação, aspectos sanitários, posse de bens duráveis e emprego.

O método utilizado nesse estudo segue os seguintes passos: I) estabelecimento de indicadores que constituem o sub-índice de qualidade de vida, com seus respectivos escores e pesos às variáveis que integram cada indicador; II) organização de postos posicionados em ordem crescente de valores, partindo-se da situação onde o indicador é menos expressivo até a situação em que poderia atingir o seu melhor desempenho.

Foram feitas algumas adaptações ao índice utilizado como base, caso da inclusão no questionário de perguntas relacionadas com o emprego e transporte escolar.

Os escores expressam a situação dos funcionários na escala ascendente de posto e matematicamente, o sub-índice social que expresse a condição social dos empregados da fruticultura (IQV) da seguinte forma:

$$
\mathrm{IQV}=1 / \mathrm{n} \sum_{\mathrm{j}=1}^{\mathrm{n}} \frac{\sum_{\mathrm{i}=1}^{\mathrm{m}} E_{i j} \cdot P i j}{\sum_{\mathrm{i}=1}^{\mathrm{m}} E_{\max _{i}} \cdot P \max _{i}}
$$


Onde: $\mathrm{E}_{\mathrm{ij}}=$ Escore do i-ésimo indicador alcançado pelo j-ésimo produtor; $\mathrm{Pij}$ $=$ Peso do i-ésimo indicador alcançado pelo j-ésimo produtor; $\mathrm{i}=1, \ldots \ldots . \mathrm{m} ; \mathrm{j}=1, \ldots \ldots$. , $\mathrm{n}, ; \mathrm{P} \max \mathrm{i}=$ Peso máximo do i-ésimo indicador; $\mathrm{E} \max \mathrm{i}=$ Escore máximo do i-ésimo indicador; $\mathrm{n}=$ número de funcionários $\mathrm{m}=$ número de indicadores. Considerou-se que os indicadores têm pesos iguais.

Embora contendo algum componente arbitrário, o (IQV) acima de um determinado grupo pode assumir valores entre zero e um e classifica-se os grupos nos seguintes níveis:

- Bom nível de qualidade de vida: se $0,80<\mathrm{IQV} \leq 1,00$;

- Médio nível de qualidade de vida: se $0,50<\mathrm{IQV} \leq 0,80$;

- Baixo nível de qualidade de vida: se $0<\mathrm{IQV} \leq 0,50$.

\subsubsection{Operacionalização das variáveis para efeito de composição do IQV}

Para efeito de aferição dos valores indicativos do IQV dos funcionários pesquisados, considerou-se:

1) Educação

Este indicador foi mensurado considerando-se a presença ou ausência de escola e a existência ou não de transporte escolar nos municípios de residência dos funcionários:

I) Disponibilidade de ensino no município:

a) Ausência de escola pública.

b) Existência de escola de ensino fundamental..............1

c) Existência de escola de ensino médio.........................2

II) Existência de transporte escolar:

a) Não há transporte escolar

b) Há transporte escolar. .1

O somatório das pontuações dos sub-itens I e II gerou o escore equivalente à variável acima citada.

2 ) Saúde

Para este indicador, foi considerada a disponibilidade de serviços de saúde no município de residência do funcionário:

a) Ausência de atendimento médico e ambulatorial.....0

b) Atendimento de primeiros socorros........................1

c) Atendimento por agente de saúde.............................2

d) Atendimento médico................................................

3) Habitação

$\mathrm{Na}$ determinação deste indicador, consideraram-se os aspectos de moradia do funcionário no que se refere a tipo de construção da residência e fonte de energia: 
I) Tipo de construção da residência:

a) Casa de taipa, coberta de palha ou telhas. .0

b) Casa de tijolo, sem reboco e piso..........................1

c) Casa de tijolo, com reboco e piso..........................2

II ) Tipo de iluminação:

a) Lampião a querosene ou lamparina e/ou velas. ..0

b) Energia elétrica. 1

O somatório das pontuações dos sub-itens I e II formou o escore equivalente à variável acima citada.

\section{4) Aspectos Sanitários}

Este indicador foi construído a partir de três variáveis: $1^{\circ}$ ) Tipo de tratamento dado à água para consumo humano; $2^{\circ}$ ) destino dado aos dejetos humanos; e $3^{\circ}$ ) destino dado ao lixo domiciliar.

I) Tipo de tratamento dado à água para consumo humano:

a) Nenhum tratamento............................................

b) Fervida, filtrada ou com hipoclorito de sódio...............1

II ) Destino dado aos dejetos humanos:

a) Jogados a céu aberto ou enterrado. 0

b) Dirigidos a fossa ou esgoto................................1

III) Destino dado ao lixo domiciliar:

a) Lançado ao solo ou queimado.............................

b) Coletado ......................................................... 1

c) Coleta seletiva para reciclagem........................2

A totalidade das pontuações dos subitens I, II e III estabeleceu o escore para a avaliação do

referido indicador.

5) Bens Duráveis

A posse de bens de consumo duráveis foi organizada em três grupos, considerando-se o valor econômico equivalente a cada um deles:

Grupo 1: rádio, ferro de engomar, liquidificador, bicicleta, equipamento de trabalho;

Grupo 2: máquina de costura, equipamento de som, televisor não colorido, fogão a gás; Grupo 3: televisor em cores, geladeira, antena parabólica, motocicleta, carro;

a) Possui pelo menos um dos bens do grupo 1 e nenhum dos bens dos outros grupos..1

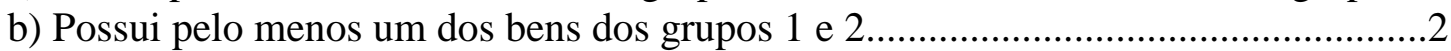

c) Possui pelo menos um dos bens do grupo 1, do grupo 2 e do grupo 3......................

6) Emprego 


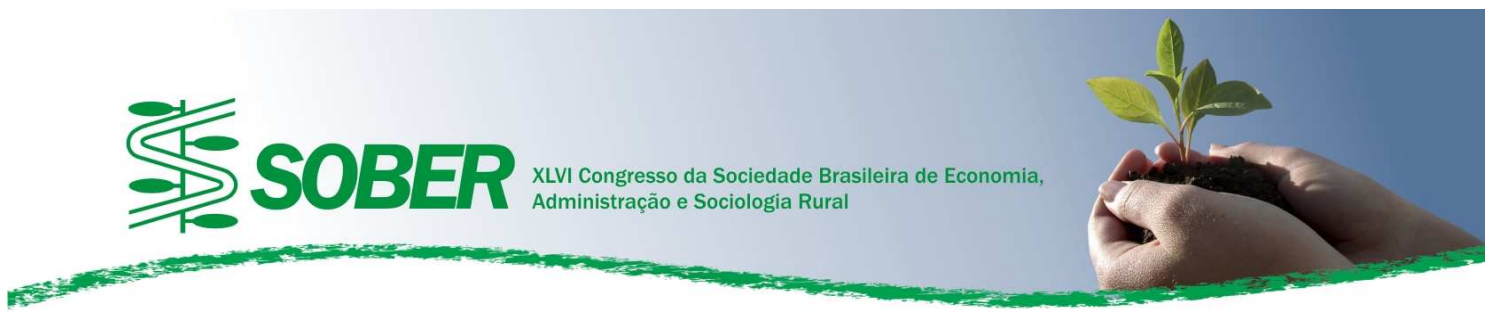

$\mathrm{Na}$ determinação deste indicador, foram considerados os itens tipo de emprego e situação do trabalhador.

I) Tipo de emprego

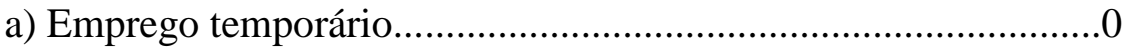

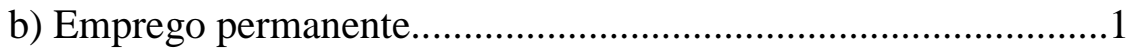

II) Situação do trabalhador

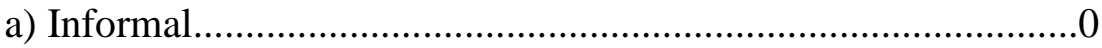

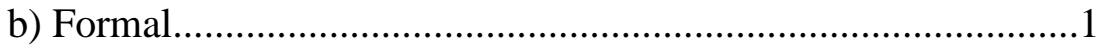

A totalidade das pontuações dos subitens I e II estabeleceu o escore para a avaliação do referido indicador.

\subsection{Dimensão ambiental}

Este componente foi baseado em trabalho de Sousa (2005), o qual considera para a sua composição, indicadores que têm sido apontados com freqüência na literatura como representativos na avaliação ambiental. Tais indicadores são: utilização de práticas de conservação do solo, método de controle de pragas e doenças utilizado na propriedade, utilização ou não de fogo em atividade agropecuária, existência de reserva de mata nativa na propriedade e utilização ou não, de práticas de manejo do solo a fim de evitar a sua degradação. Foram, entretanto, acrescentados para determinar esse subíndice alguns indicadores considerados relevantes para o caso específico desta pesquisa que se destina a avaliar empresas do ramo da fruticultura irrigada. Foram acrescentados método de irrigação utilizado e adoção ou não de análise de solo para definir adubação.

Com relação ao método do controle de pragas e doenças utilizados foram considerados também os cuidados tomados na utilização dos insumos (agrotóxicos). Os itens considerados foram, se a aplicação dos produtos era feita com base em receituário agronômico, o destino dado às embalagens e às águas de lavagem dos equipamentos, utilização de equipamento de proteção individual (EPI) pelos trabalhadores $\mathrm{e}$ calibragem de máquinas e pulverizadores.

Considerando cada item mencionado, foram estabelecidas as possíveis alternativas e a estas foram atribuídos pontos, com escopo de mensurar suas participações em relação ao meio ambiente nas unidades produtivas pesquisadas. 


$$
\begin{aligned}
& \mathrm{m} \\
& \sum E i j \\
& \text { n } \quad \mathrm{i}=1 \\
& \mathrm{IA}=1 / \mathrm{n} \sum \\
& \mathrm{j}=1 \quad \mathrm{~m} \\
& \sum E \max _{i} \\
& \mathrm{i}=1
\end{aligned}
$$

Onde:

IA = Sub-indice Ambiental;

Eij = Escore do i-ésimo indicador, alcançado pela j-ésima empresa;

$\mathrm{i}=1, \ldots, \mathrm{m} ;$ (Número de indicadores);

$\mathrm{j}=1, \ldots, \mathrm{n}$; (Número de empresas);

E max i $=$ Escore máximo do i-ésimo indicador

$\mathrm{n}=$ Número de empresas;

$\mathrm{m}=$ Número de indicadores.

O IA pode assumir valores compreendidos entre zero e um. Para proceder à comparação dos níveis de preservação ambiental adotados pelas empresas são definidos três níveis (baixo, médio e alto) formados por intervalos dos valores de IA, em idêntica escala apresentada para o sub-índice anterior.

\subsubsection{Operacionalização das variáveis para efeito de composição do índice ambiental}

As informações que deram origem a construção dos indicadores ambientais utilizados foram:

1) Utiliza alguma prática de conservação do solo? (*)

a) Não 0

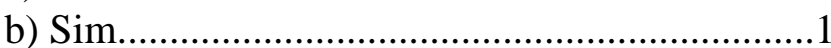

(*) Não foi considerada como prática de conservação do solo a adubação química, já que não se trata de uma prática que possa ser caracterizada como cuidado ambiental, pois caso seja feita sem as devidas precauções também pode trazer impactos negativos. Sobre essa questão há, a seguir, pergunta específica. O controle do fogo também não foi considerado como prática de conservação do solo na resposta a este item, já que, devido à sua importância, existe pergunta específica para tal aspecto.

2) Que método de controle de pragas e doenças se utiliza na unidade produtiva?

a) Agrotóxico, sem observar alguma das medidas de segurança avaliadas......0 
b) Agrotóxico observando todas as medidas de segurança avaliadas 1

c) Agrotóxico com MIP e todas as medidas de segurança avaliadas 2

b) Biológico

3) Faz utilização de fogo em atividade agropecuária?

a) $\mathrm{Sim}$ . .0

b) Não. .1

4) Existe área de reserva de mata nativa de pelo menos $20 \%$ da propriedade?

a) Não. .0

b) $\mathrm{Sim}$ 1

5) Utiliza algum sistema de manejo do solo?

a) Não. .0

b) Sim. .1

6) Qual o método de irrigação utilizado?

a) Inundação, sulcos. . .0

b) Aspersão. 1

c) Microaspersão, gotejamento 2

7) A adubação é definida com base em análise de solo?

a)Não. .0

b) $\mathrm{Sim}$

\section{4. Índice de Viabilidade Sócio-Ambiental}

A metodologia utilizada para mensurar o índice de viabilidade sócio-ambiental das empresas incorporou as dimensões social e ambiental, através dos seguintes subíndices:

a)Sub-Índice Social (IQV), abrangendo os indicadores de educação, saúde, habitação, aspectos sanitários, posse de bens de consumo duráveis e emprego;

b) Sub-Índice Ambiental, compreendendo os aspectos relativos à adoção de práticas conservacionistas do solo, controle fitossanitário, preservação de área de reserva ambiental, sistema de irrigação utilizado, uso do fogo em atividade agropecuária, adoção de técnicas de manejo do solo e utilização de análise de solo.

Assim, o Índice de Viabilidade sócio-ambiental (IV) foi composto por:

$\mathrm{k}$

$$
\mathrm{IV}=1 / \mathrm{k} \sum_{\mathrm{h}=1} \mathrm{I}_{\mathrm{h}}
$$




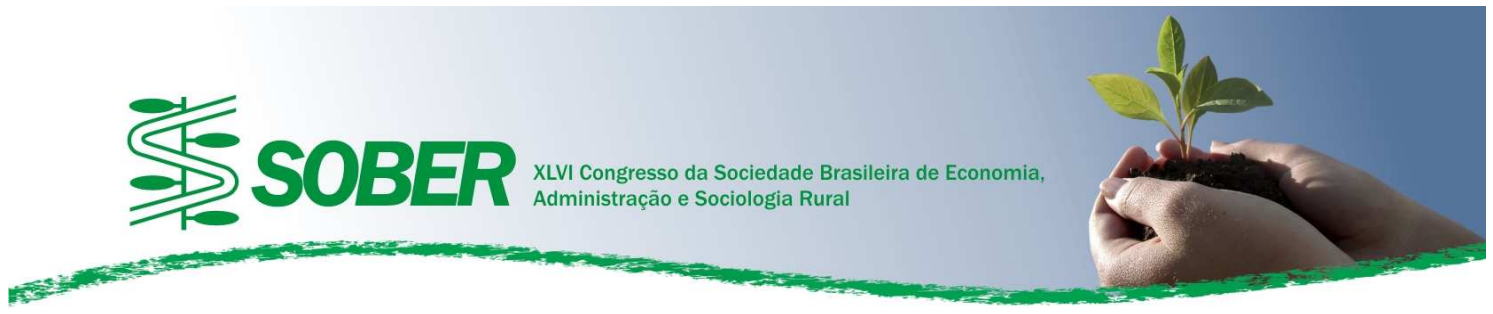

Onde:

IV = Índice de Viabilidade sócio-ambiental;

I = Escore do h-ésimo índice;

$\mathrm{h}=1, \ldots, \mathrm{k}$

$\mathrm{k}=$ Número de Índices.

\section{RESULTADOS E DISCUSSÃO}

\subsection{Qualidade de Vida dos Funcionários das Empresas}

Todos os funcionários entrevistados residem em municípios onde existem escolas de ensino fundamental e de ensino médio. Em todos os municípios de residência existe transporte escolar para os estudantes que residam longe da escola. Apenas um dos entrevistados informou não haver regularidade no serviço de transporte escolar em sua localidade. Os mesmos entrevistados admitem que no município de residência, existe atendimento médico.

No tocante as condições de moradia, 63,3\% dos entrevistados moram em casas de tijolo com reboco e piso, 26,7\% residem em casas de tijolo sem reboco e piso, e 10\% moram em casas de taipa. Quanto ao tipo de iluminação da residência, 93,3\% dos funcionários entrevistados têm energia elétrica na residência e 6,7\% utilizam lampião, lamparina e/ou velas. $\mathrm{O}$ fato da quase totalidade dos entrevistados ter o fornecimento de energia elétrica na residência é bastante positivo, pois possibilita a utilização de luz elétrica e de eletrodomésticos, propiciando uma melhoria na qualidade de vida das famílias.

Quanto aos Aspectos Sanitários e de Higiene 86,7\% dos entrevistados afirmaram que a água é filtrada, fervida ou tratada com hipoclorito de sódio. Já 13,3\% dos entrevistados afirmaram que a água para consumo humano não recebe nenhum tipo de tratamento.

Sobre o destino dos dejetos humanos, constatou-se que na residência de $90 \%$ dos entrevistados o destino é fossa ou esgoto. Para 10\% dos entrevistados os dejetos são jogados a céu aberto ou enterrados.

Em relação ao lixo domiciliar, para $60 \%$ dos entrevistados o lixo é coletado enquanto para $40 \%$ o lixo é lançado ao solo ou queimado. Em nenhum dos municípios de residência há coleta seletiva para posterior reciclagem de lixo domiciliar.

A posse de bens de consumo duráveis foi considerada para analisar o nível de renda dos funcionários das empresas, sendo os bens divididos em três grupos, de acordo com o valor econômico de cada um.

Entre os funcionários entrevistados $80 \%$ possuem bens do grupo 1, do grupo 2 e do grupo 3 e apenas $10 \%$ possuem bens do grupo 1 e do grupo 2 e nenhum bem do grupo 3 . E os demais $10 \%$ possuem somente bens do grupo 1 e nenhum bem dos outros grupos.

Em relação ao tipo de emprego, constatou-se que entre os funcionários entrevistados $60 \%$ são empregados temporários e os outros $40 \%$ são empregados permanentes. Já quanto à situação do trabalhador, 96,7\% dos funcionários entrevistados são empregados formais, ou seja, têm carteira assinada e 3,3\% são informais. A maioria 


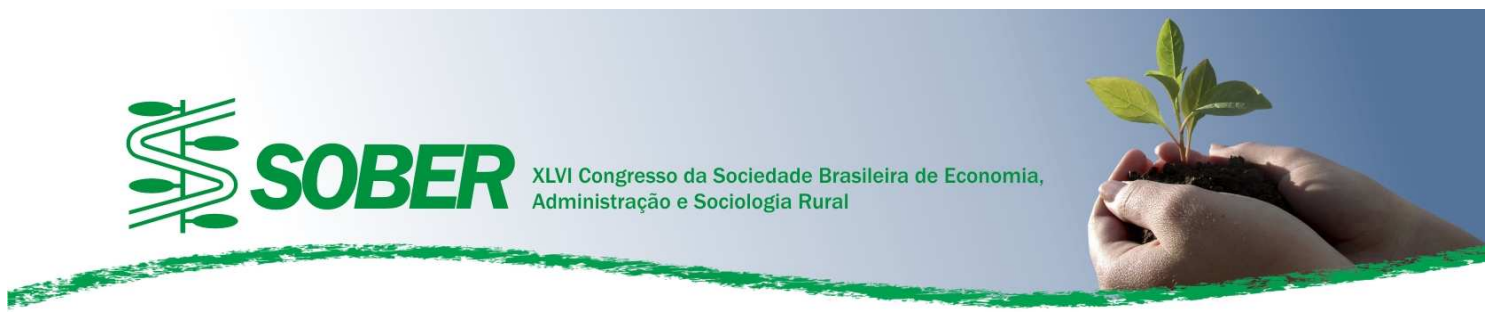

dos empregos na fruticultura irrigada na região é temporário porque a principal cultura, o melão, é uma cultura temporária.

Os funcionários temporários passam geralmente seis meses empregados, de julho a dezembro, e seis meses sobrevivendo do seguro desemprego que recebem durante três meses. Os trabalhadores permanentes encontram-se, na maioria, em empresas que trabalham com culturas permanentes, como por exemplo, manga e banana.

Vê-se, portanto, que o aumento da área com culturas permanentes seria benéfico, sobretudo, do ponto de vista da qualidade do emprego. Seria desejável, portanto, a formulação de políticas públicas que incentivassem esse tipo de cultura, a fim de favorecer a criação de empregos durante o ano todo. Quanto à situação dos trabalhadores dessas empresas, a pesquisa demonstrou que a quase totalidade deles têm carteira assinada, o que sem dúvidas é muito positivo do ponto de vista social.

Dentre os indicadores utilizados para compor o sub-índice (IQV), observouse que aquele que obteve os melhores resultados entre os funcionários entrevistados foi em relação a saúde e o segundo foi educação. Vale ressaltar que os municípios visitados, embora com a presença de bolsões de pobreza são os mais dinâmicos do Ceará.

O terceiro indicador em resultados foi à posse de bens duráveis, grande parte dos entrevistados possui estes bens de todos os grupos contemplados na entrevista.

A habitação vem em quarto lugar no que diz respeito aos resultados entre os entrevistados. Uma boa parte dos funcionários da amostra reside em casas de tijolo com reboco.

O emprego vem em quinto lugar. Isso se deve ao fato de a maioria dos funcionários ser empregado temporário nas empresas. O ideal, certamente, seria que a duração desses empregos se estendesse por todo o ano. Entretanto, é preciso reconhecer que, diante da escassez de oportunidades verificadas no meio rural do Nordeste brasileiro, especialmente no Ceará, os empregos temporários gerados pelas empresas produtoras de frutas já representam algo auspicioso.

Os aspectos sanitários vêm em último lugar em resultados entre os indicadores que compõem o índice de qualidade de vida. Isso se deve, sobretudo, ao item "destino do lixo domiciliar", que é em alguns casos jogado a céu aberto ou queimado, destinações que não se encontram entre as mais adequadas. Além disso, em nenhum dos municípios de residência há coleta seletiva para posterior reciclagem de lixo domiciliar.

O índice de qualidade de vida total para a presente amostra, calculado a partir dos dados das entrevistas, foi de 0,8259 , sendo portanto considerado bom.

\subsection{Cuidados Ambientais das Empresas}

Cerca de $83,3 \%$ das empresas visitadas utilizam alguma prática de conservação do solo, enquanto $16,7 \%$ não utilizam nenhuma prática. Ressalte-se que na área de estudo a terra é o ativo mais valorizado e apresentou o maior incremento de valor nos últimos 10 anos em relação a todo nordeste. As práticas mais citadas foram 


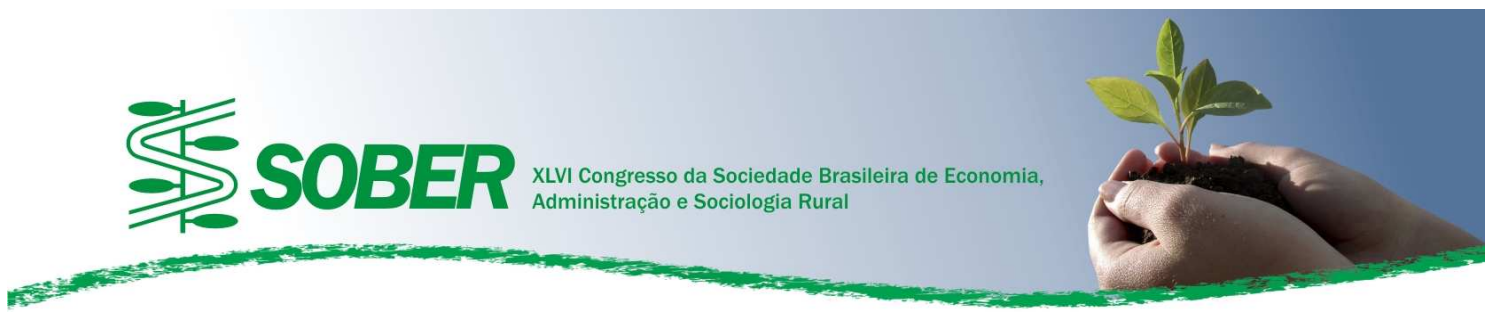

adubação orgânica e quebra-ventos. As práticas mecânicas não são, em geral, utilizadas na região, pois o relevo ali é predominantemente plano.

Quanto ao uso de fogo em atividades agropecuárias entre as seis empresas visitadas, cinco afirmaram não utilizar fogo de maneira alguma em atividade agropecuária. A única empresa que faz utilização de fogo realiza-a de modo controlado, com enleiramento do material a ser queimado, somente para reduzir o grande volume de restos culturais. Tal empresa é a única que trabalha com a cultura da banana. Tal nível de conscientização, muitas vezes não se verifica entre agricultores familiares.

Em cinco das seis empresas visitadas $(83,3 \%)$, existe área de reserva de mata nativa de pelo menos $20 \%$. Em uma das empresas $(16,7 \%)$, a reserva legal não equivale à percentagem mínima de $20 \%$ recomendada por lei. Em tal empresa a reserva legal abrange somente $8 \%$ da área total da propriedade. A reserva legal, portanto, também é um aspecto que vem sendo observado pela grande maioria das empresas visitadas, e contribui para a conservação da biodiversidade local, bem como para a preservação das águas subterrâneas e diminuição das enxurradas e da erosão.

Todas as empresas visitadas utilizam métodos de irrigação poupadores de água, tais como o gotejamento e a micro aspersão. Isso é muito importante, pois além de contribuir para o uso eficiente de um recurso tão escasso na região, também evita a ocorrência de salinização dos solos, possibilitando a utilização mais duradoura. Além disso, prestam-se como unidades demonstrativas e ajudam na difusão em toda a região de tecnologias poupadoras de água.

Quanto à adubação, todas as empresas visitadas afirmaram definir a adubação com base em análise de solo, o que demonstra a prática de uma agricultura racional e amparada pelos recursos tecnológicos. Todas também utilizam algum sistema de manejo do solo, sendo apontados à rotação de culturas, pousio e preparo mínimo do solo para plantio.

Quanto ao controle de pragas e doenças nas propriedades, com auxílio de agrotóxicos e sem tomar alguma das medidas de segurança avaliadas, $16,7 \%$ faz tal controle com agrotóxicos e tomando todos os cuidados avaliados na pesquisa. $66,6 \%$ controlam pragas e doenças com agrotóxicos, utilizando também o manejo integrado de pragas (MIP), além de todas as medidas de segurança avaliadas.

Em todas as empresas visitadas, portanto, tal controle é feito com auxílio de agrotóxicos, nenhuma delas trabalha com a agricultura orgânica. Apenas uma das seis empresas visitadas não tem procedimento correto em relação a um tipo de cuidado considerado no uso de agrotóxicos. A aplicação de agrotóxicos é feita com base em receituário agronômico em todas as propriedades visitadas.

Quanto ao destino das embalagens, todas as empresas afirmaram haver galpão específico para as embalagens vazias de tais produtos, até que sejam recolhidas a central de recebimento. Em relação ao destino das águas de lavagem dos equipamentos de aplicação, cinco das seis empresas visitadas afirmaram que a água tem destinação específica, sendo destinada a local construído especificamente para tal fim. Em uma das empresas, a menor delas, a referida água é conduzida a local afastado das culturas, onde é derramada no solo.

No que se refere à utilização do equipamento de proteção individual (EPI) pelos trabalhadores, todas as empresas visitadas afirmaram que os trabalhadores 


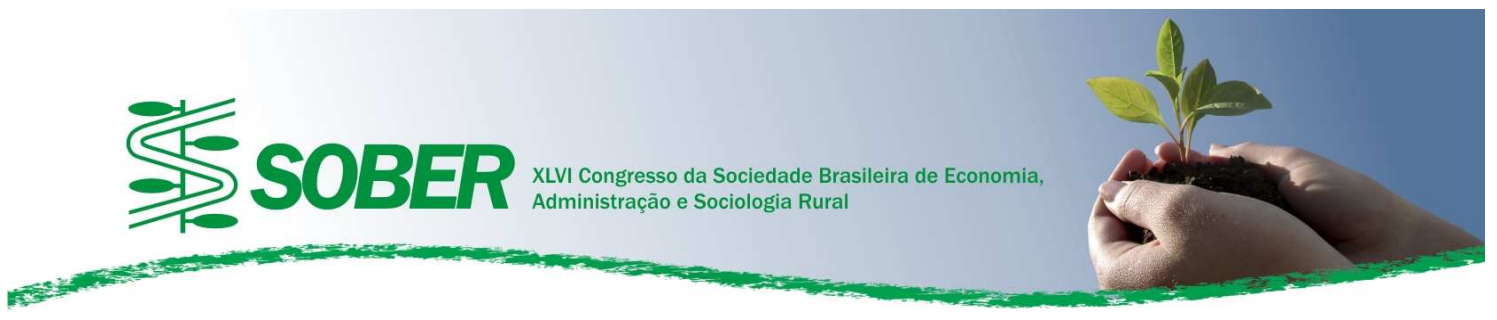

utilizam tal equipamento e todas fazem a calibragem e limpeza regular de máquinas e pulverizadores.

Entre os indicadores avaliados para compor o índice ambiental, os melhores resultados obtidos foram dos seguintes itens: utilização de fogo em atividade agropecuária, método de irrigação utilizado, adubação baseada em análise de solo e existência de sistema de manejo do solo. Em seguida, em matéria de desempenho, encontram-se os itens utilização de prática de conservação do solo e existência de reserva de mata nativa na propriedade. Em último lugar, com resultados menos positivos vem o controle de pragas e doenças. Isto se deve ao fato de todas as unidades produtivas pesquisadas utilizarem agrotóxicos nesse controle.

$\mathrm{O}$ valor do Índice Ambiental, calculado para o conjunto das empresas visitadas, foi de 0,8166, que evidencia cuidados ambientais adequados. O valor satisfatório encontrado para o índice ambiental está, certamente, relacionado ao fato de metade das empresas visitadas possuírem certificações exigidas atualmente por mercados internacionais. Para serem concedidas, tais certificações exigem do produtor uma série de cuidados, incluindo diversos cuidados ambientais.

Entre as certificações possuídas por uma parte das empresas visitadas estão o Eurepgap e o Tesco Nature Choice (TNC). Três das seis empresas visitadas têm a certificação Eurepgap. Entre essas três, duas possuem também a certificação TNC. É importante mencionar, inclusive, que para manterem essas certificações, as empresas precisam passar por inspeções periódicas. Assim, precisam estar sempre em conformidade com as normas, a fim de não perderem os certificados conquistados. Entre aquelas empresas que não possuíam nenhum tipo de certificação, uma estava se preparando para se adequar às normas do Eurepgap, a fim de obter o certificado.

\section{3. Índice de Viabilidade Sócio-Ambiental}

O valor encontrado para o Índice de Viabilidade Sócio-Ambiental, composto pelos Índices Ambiental e de Qualidade de Vida foi de 0,8212. Esse valor situa a fruticultura irrigada desenvolvida por empresas no Baixo Jaguaribe num patamar de boa viabilidade sócio-ambiental. Ambos os índices que compuseram o índice final obtiveram resultados satisfatórios, situando-se em níveis elevados.

\section{CONCLUSÕES}

A realização da pesquisa e o cálculo dos índices permitiram um maior conhecimento sobre as condições de vida dos trabalhadores da fruticultura irrigada na região do Baixo Jaguaribe. Também foi possível identificar os principais cuidados ambientais tomados pelas empresas nas propriedades onde é desenvolvida a atividade.

Constatou-se que a fruticultura gera um número significativo de empregos na região. O resultado do Índice de qualidade de vida foi 0,8259 , situa o grupo pesquisado num bom nível de condições de vida. Tal resultado é superior ao que se esperava antes da pesquisa e mostra que as condições de vida dos trabalhadores da fruticultura irrigada da região são adequadas. Acredita-se que tal nível de atendimento das necessidades básicas das pessoas se deve ao fato de essa ser uma área favorecida pela prosperidade da agricultura irrigada. A renda proporcionada pelo emprego na atividade possibilita melhores condições de habitação, bem como um melhor nível de 


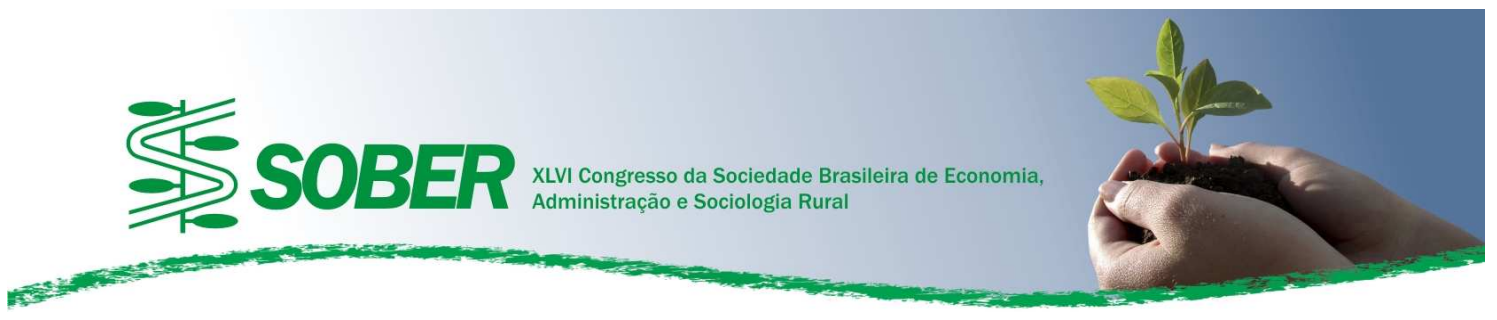

consumo. Além disso, as condições que dependem de serviços públicos essenciais, tais como educação, saúde, fornecimento de energia elétrica e coleta de lixo, têm sido, em geral, asseguradas. Entre estas, somente a última, coleta de lixo, não beneficia atinge a grande maioria dos entrevistados, donde se conclui que deve ser focalizada com mais atenção pelas autoridades.

A esses serviços também se deve o bom resultado encontrado para o Índice de Qualidade de Vida. Deve-se lembrar que, apesar de verificar sua existência, esta pesquisa não chegou a avaliar a qualidade de tais serviços. Quanto aos empregos, o fato de a quase totalidade dos entrevistados ter emprego formal, com carteira assinada, é muito positivo. Entretanto, a maioria deles é empregado temporário, permanecendo no emprego somente durante parte do ano.

No que diz respeito ao índice Ambiental, para este também se obteve um bom resultado $(0,81660)$ situando o público pesquisado num bom nível de condições ambientais, o que novamente superou as expectativas anteriores à pesquisa. A busca, pelas empresas, de certificações, exigidas atualmente por mercados internacionais, certamente tem contribuído para uma maior preocupação com os aspectos ambientais da produção. A metade das empresas visitadas possui certificações que, para serem obtidas e mantidas, exigem o cumprimento de diversas normas técnicas, incluindo uma série de cuidados ambientais. Em contrapartida, tais certificações possibilitam a venda para mercados internacionais exigentes, como a Europa, por exemplo.

Mesmo com as limitações que envolvem a construção de índices a pesquisa permitiu conhecer melhor as condições de vida dos trabalhadores e os cuidados ambientais tomados numa atividade que tem crescido no Estado e que vem sendo vista como uma importante alternativa para o desenvolvimento da região. Os resultados obtidos levam a crer que a atividade está no caminho certo, que a fruticultura irrigada é, de fato, uma atividade que tem contribuído positivamente para o desenvolvimento da região. Tal atividade merece, assim, atenção especial dos formuladores de políticas públicas, a fim de que possa desenvolver todo o seu potencial, sempre com respeito ao trabalhador e ao ecossistema.

É importante incentivar a exploração de culturas permanentes nas unidades produtivas, pois estas são mais propensas a criarem empregos permanentes, que proporcionem aos funcionários ocupação durante o ano todo. Também é importante fortalecer os órgãos de fiscalização ambiental, para que estes possam fazer cumprir a legislação ambiental vigente, e incentivar a adoção de práticas de produção orgânica, bem como conscientizar a população sobre sua importância.

A agricultura irrigada é uma atividade importante para o Nordeste porque pode gerar efeitos sócio-econômicos substanciais. Assim, é fundamental torná-la cada vez mais socialmente justa, assegurando a todos que nela trabalham condições de vida adequadas, e ambientalmente viável, para que se desenvolva em harmonia cada vez maior com o ambiente.

Um aspecto conclusivo importante é que não se pode negligenciar a influencia positiva do mercado externo, cuja adoção de medidas protecionistas certamente contribuem para que os fruticultores exportadores adotem medidas sociais e ambientais politicamente corretas como é o caso, por exemplo, da exigência de 
certificação, rastreabilidade para controle de uso de agrotóxicos e uso do trabalho escravo e infantil.

\section{REFERÊNCIAS BIBLIOGRÁFICAS}

BERTONI, J.; LOMBARDI, F. Práticas conservacionistas e sistemas de manejo. In: Conservação do Solo. $2^{a}$ ed. São Paulo: Ícone, 1990. cap. 8, p. 94-182.

BRUSEKE, F. O problema do desenvolvimento sustentável. In: CAVALCANTI, C. (Org.).

Desenvolvimento e Natureza: estudos para uma sociedade sustentável. São Paulo: Cortez;

Recife: Fundação Joaquim Nabuco, 1995. p. 29-40.

CARVAlho, J. M. Pólo de Desenvolvimento Integrado Baixo Jaguaribe: Informações

Estratégicas. Fortaleza: Banco do Nordeste do Brasil S. A., 2003. 156 p.

CLARO, P.; CLARO, D.; AMÂNCIO, R.. Sustentabilidade e Indicadores: Um Estudo de

Caso com Torrefadoras de Café. In: International PENSA Conference on Agri-food Chains/Networks Economics and Management, 2005, Ribeirão Preto.

DAMIANI, O. Diversificação Agrícola e redução de Pobreza: A Introdução no Nordeste

Brasileiro de Produtos Agrícolas Não-Tradicionais de Alto Valor e seus Efeitos sobre Pequenos Produtores e Trabalhadores rurais Assalariados. Revista Econômica do Nordeste, Fortaleza, v. 34, n. 1, p. 42-73, jan./mar. 2003.

FRANÇA, Francisco Mavignier Cavalcante (Coord.). A Importância do agronegócio da

irrigação para o desenvolvimento do Nordeste. Fortaleza: Banco do Nordeste do Brasil, 2001. 113 p.

GIL, A. C. Metodos e técnicas de pesquisa social. 5. ed. São Paulo: Atlas, 1999. 206p.

GONDIM, R. S. et al. Diagnóstico da Agricultura Irrigada no Baixo e Médio Jaguaribe. Revista Econômica do Nordeste, Fortaleza, v. 35, n. 3, p. 424-430, jul./set. 2004.

KHATOUNIAN, C. A. A Reconstrução Ecológica da Agricultura. Botucatu: Agroecológica, 2001. 348 p. 
MAROUELLI, R. P. O Desenvolvimento Sustentável da Agricultura no Cerrado Brasileiro; Brasília, 2003. Disponível em: <http://www.iica.org.br/Docs/Publicacoes/PublicacoesIICA/RodrigoMarouelli.pdf $>$.

MELO, A. S. S. A Estimação de um Índice de Agricultura Sustentável: Uma Aplicação para a Área Irrigada do Vale do Submédio São Francisco. 1999. 166 p. Tese (Doutorado em Economia) - Programa de Pós-Graduação em Economia PIMES, Recife, 1999.

RODRIGUES, M. T. Agronegócios: Histórico e Conceitos. Fortaleza: Banco do Nordeste do Brasil S. A., 2001.

SOUSA, M. C. Sustentabilidade da Agricultura Familiar em Assentamentos de Reforma Agrária no Rio Grande do Norte. Revista Econômica do Nordeste, Fortaleza, v. 36, n. 1, jan./mar. 2005. 